\title{
Apremilast Uses and Relevance to the Military
}

\author{
Nathanael E. Hathaway, MD; Willis Hughes Lyford, MD
}

\section{PRACTICE POINTS}

- Apremilast is a versatile and easy-to-use therapeutic option for treatment of psoriasis and psoriatic arthritis.

- Ease of transport and storage as well as lack of necessary laboratory monitoring have made apremilast a compelling treatment option for psoriasis and psoriatic arthritis in military populations with high operational tempos.

- Dermatologists should consider apremilast for treatment in populations that work for prolonged periods in austere or resource-limited environments.

Apremilast is a small-molecule biologic approved by the US Food and Drug Administration (FDA) for use in plaque psoriasis, psoriatic arthritis, and Behçet disease. Although apremilast is seemingly a less favorable choice for treating psoriasis in the era of injectable biologics, the drug is an important option for patients in the military. In this article, we review on-label indications and off-label uses for apremilast; highlight the importance of apremilast for managing psoriasis in the military population; and propose other patient populations in whom the use of apremilast is favorable. We also present a case report that highlights and embodies the benefit of apremilast for military service members.

Cutis. 2021;107:216-220.

A premilast is a small-molecule biologic approved by the US Food and Drug Administration (FDA) for use in plaque psoriasis, psoriatic arthritis, and Behçet disease. ${ }^{1-6}$ Although apremilast is seemingly a less favorable choice for treating psoriasis in the era of injectable biologics, the drug is an important option for patients in the military. In recent months, apremilast also emerged as one of a few systemic medications recommended for the treatment of psoriasis and other dermatologic conditions during the COVID-19 pandemic. $^{7}$
In this article, we review on-label indications and off-label uses for apremilast; highlight the importance of apremilast for managing psoriasis in the military population; and propose other patient populations in whom the use of apremilast is favorable. We also present a case report that highlights and embodies the benefit of apremilast for military service members.

\section{CASE REPORT}

A 28-year-old active-duty male US Navy service member developed extensive guttate psoriasis in a distribution too wide to manage with topical medication (Figure, A-C). His condition did not improve with a trial of oral antibiotics, and he reported itch that affected his sleep. He denied new joint pain, swelling, or deformity.

A review of the patient's service history revealed that he was serving aboard a guided-missile cruiser ship for a tour extending an additional 2 years. Limited medical resources and lack of refrigeration made the use of injectable biologics, such as adalimumab, infeasible. Furthermore, the patient was too critical to the mission to be transported frequently off the ship to a higher level of care for injection of medication. He also had trouble returning for appointments and refills because of the high operational tempo of his command.

After discussion with the patient, oral apremilast was started at $30 \mathrm{mg} / \mathrm{d}$ and titrated up to the standard dosing of $30 \mathrm{mg}$ twice daily, with excellent results by 3 months after he started therapy (Figure, D-F).

\section{COMMENT}

We reviewed the research on apremilast for its approved indications, including psoriasis; its off-label uses; and strategies for using the drug to treat psoriasis and other dermatologic conditions in military populations. The most recent evidence regarding the use of apremilast in

From the Department of Dermatology, Naval Medical Center San Diego, California.

The authors report no conflict of interest.

The opinions and assertions contained herein are the private views of the authors and are not to be construed as official or as reflecting the views of the US Navy, US Army, US Department of Defense, or the US government.

Correspondence: Nathanael E. Hathaway, MD, Naval Medical Center San Diego, Department of Dermatology, 34800 Bob Wilson Dr, Bldg 2, 3rd Floor, San Diego, CA 92134 (nathanael.e.hathaway.mil@mail.mil).

doi:10.12788/cutis.0231 

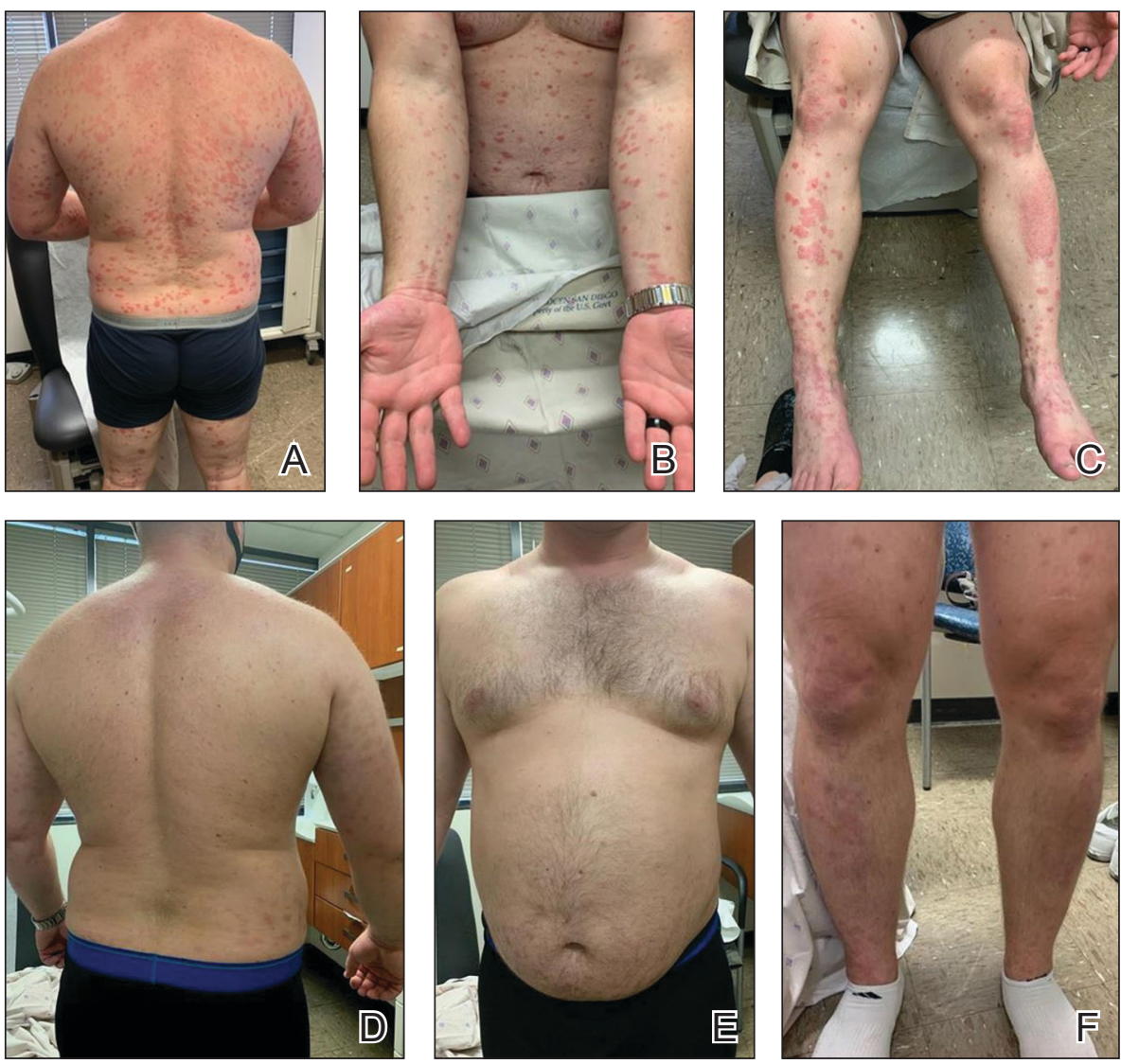

dermatology, rheumatology, and other medical specialties was assessed using published English-language research data and review articles. We conducted a PubMed search of articles indexed for MEDLINE using the following terms: apremilast, Otezla, psoriasis, psoriatic arthritis, arthritis, off-label, Behçet's, hidradenitis suppurativa, military, and armed forces. We also reviewed citations within relevant articles to identify additional relevant sources.

Off-label uses reviewed here are based on data from randomized controlled trials, large open-label trials, and large prospective case series. Articles with less evidence are not included in this review.

\section{On-Label Usage Profile}

Apremilast is an orally administered, small-molecule inhibitor of phosphodiesterase 4. Small-molecule inhibitors are a class of medications with low molecular weight, high stability, and short half-life. They act intracellularly to modulate proinflammatory states through regulation of the proinflammatory cytokine milieu.

Apremilast has been approved by the FDA for use in adult psoriasis and psoriatic arthritis since 2014 and for use in treating oral ulcers of Behçet disease since 2019. ${ }^{1-3,5,6}$ Recently, a phase 2, multicenter, open-label study on the use of apremilast in pediatric psoriasis patients (aged 12-17 years) demonstrated a similar safety profile with weight-based dosing8; phase 3 trials in this population are in the recruitment phase (ClinicalTrials.gov Identifier NCT03701763).

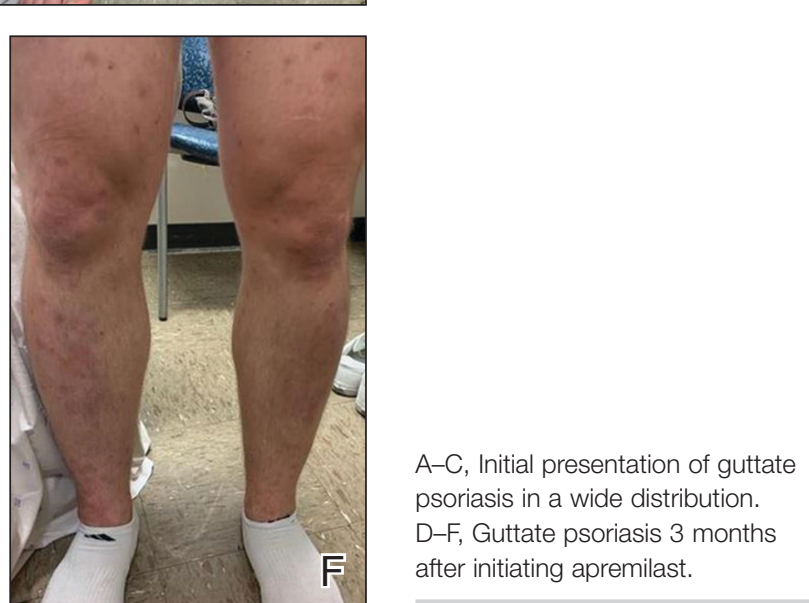

Because information regarding its use in pregnancy is limited, apremilast is not recommended in this population. It is unknown whether apremilast is present in breast milk; although the manufacturer does not make explicit recommendations regarding use during breastfeeding, an expert panel reviewing management of psoriasis in pregnant and breastfeeding women recommended avoiding its use while breastfeeding. ${ }^{9}$

\section{Common Adverse Effects}

Common adverse effects (AEs) include weight loss ( $>5 \%$ total body weight in $5 \%$ of patients; $5 \%-10 \%$ of total body weight in $10 \%-12 \%$ of patients; and $\geq 10 \%$ total body weight in $2 \%$ of patients), diarrhea and nausea, headache, and upper respiratory tract infection. ${ }^{10,11}$ Gastrointestinal AEs tend to be self-limited and improve or resolve after the first few weeks of therapy. Caution is advised in patients older than 65 years and in those at risk for hypotension or volume depletion. Although depressed mood is a rare $\mathrm{AE}(<1 \%)$, apremilast should be used cautiously in patients with a history of depression or suicidal ideation. Weight loss generally is self-limited; routine monitoring of weight is recommended. ${ }^{11}$

\section{Apremilast in Psoriasis and Psoriatic Arthritis}

Psoriasis-The ESTEEM trials established the safety and efficacy of apremilast for use in psoriasis. ${ }^{2,3}$ In a phase 3, multicenter, double-blind, placebo-controlled trial of 
844 patients, apremilast demonstrated a statistically significant $75 \%$ or greater reduction from the baseline psoriasis area and severity index score (PASI-75) in 33.1\% of patients receiving the medication compared to $5.3 \%$ of those receiving placebo. ${ }^{2}$ Data from real-world practice (outside constraints of clinical trials) suggest slightly greater efficacy than was demonstrated in the ESTEEM trials.

A recently published retrospective, cross-sectional study of 480 patients with psoriasis treated with apremilast reported that $48.6 \%$ of patients continuing therapy for a mean (SD) of 6 (1) months achieved PASI-75. Furthermore, the mean dermatology life quality index (DLQI) score of the surveyed population decreased from 13.4 at initiation of treatment to 5.7 at 6 (1) months of treatment-a marked improvement in quality of life. ${ }^{12}$ Other single-center and smaller study populations also have suggested increased realworld benefit. ${ }^{13,14}$

Nonetheless, the rate and degree of clearance of plaques with apremilast seem to lag behind what is observed with many of the biologics and traditional medications employed to treat psoriasis. ${ }^{15-19}$ Furthermore, indirect cost analysis comparisons suggest a much higher cost per level of PASI for apremilast compared to several biologics and to methotrexate. ${ }^{20,21} \mathrm{~A}$ study that used indirect methods of comparison to analyze the comparative cost and efficacy of apremilast and methotrexate found no evidence of greater efficacy for apremilast and that the incremental cost to achieve 1 additional PASI-75 responder by using apremilast is $\$ 187,888$ annually. ${ }^{21}$

Psoriatic Arthritis-The PALACE clinical trials 1, 2, and 3 assessed the efficacy of apremilast in patients who

\section{Evidence for Off-Label Use of Apremilast ${ }^{24-32}$}

\section{Condition Evidence for apremilast \\ AD Phase 2 RCT of adults with moderate to severe AD showed a 15\%-20\% improvement in the EASI score, with a slight advantage when using higher (40 mg twice daily) dosing ${ }^{24}$ \\ Open-label pilot study of 16 adult patients showed notable improvement in EASI, itch VAS, and DLQI; 50\% (5/10) of patients treated for 6 mo improved $\geq 1$ point on the IGA scale at $30 \mathrm{mg}$ twice daily dosing ${ }^{25}$ \\ Open-label trial of 10 patients with $\mathrm{AD}$ and allergic contact dermatitis found that apremilast 20 mg twice daily was minimally effective in AD but well tolerated, with 20\% (2/10) of patients improving by $\geq 2$ points on the IGA scale and $10 \%$ achieving EASI-75 (ie, $\geq 75 \%$ reduction from baseline EASI score) ${ }^{26}$}

HS Small RCT of 20 patients with moderate HS who were treated for 16 wk with apremilast 30 mg twice daily found that $53 \%(8 / 15)$ in the treatment arm had clinically meaningful but not statistically significant improvement in pain, itch, and lesion count ${ }^{27}$

Open-label phase 2 study of 20 patients with mild to moderate HS receiving apremilast $30 \mathrm{mg}$ twice daily found that $65 \%(13 / 20)$ achieved $a \geq 50 \%$ reduction in the inflammatory lesion count on the HiSCR end point and notable improvement in pain and $\mathrm{QOL}^{28}$

Lichen Small open-label trial of 10 patients with biopsy-proven lichen planus taking apremilast 20 mg twice daily found that planus $\quad 3$ patients achieved the primary end point of improvement of $\geq 2$ points in the PGA score from baseline to week 12; improvement in several other secondary end points related to QOL was noted ${ }^{29}$

Rosacea Small open-label trial of 10 patients with moderate to severe erythematotelangiectatic and papulopustular rosacea taking apremilast $20 \mathrm{mg}$ twice daily showed no significant difference between baseline pustule count and pustule count after 12 wk of therapy; there was significant improvement in several secondary end points related to QOL $(\mathrm{PG}-7 \mathrm{~A}[P=.02] \text {, POES }[P=.001] \text {, erythematotelangiectatic rating }[P=.005])^{30}$

Alopecia Double-blind, placebo-controlled, single-center pilot study in 30 moderate to severe alopecia areata patients areata $\quad(250 \%$ scalp involvement) that were randomized 2:1 to receive apremilast $(n=20)$ or placebo $(n=10)$ orally for 24 wk (30 mg twice daily); no significant difference was seen $(P=.38)$, and only $8.3 \%(1 / 12)$ of patients who continued the study had met the primary end point ${ }^{31}$

Cutaneous Open-label trial of 15 patients taking apremilast $20 \mathrm{mg}$ twice daily found significant $(P<.005)$ improvement in sarcoidosis induration of lesions compared to baseline; no significant difference in other components of the SASI score (erythema, desquamation, and involved area) was noted; normalized mean rating of photographs taken by investigators after 12 wk of treatment was somewhat better than before therapy ${ }^{32}$

Abbreviations: AD, atopic dermatitis; RCT, randomized controlled trial; EASI, Eczema Area and Severity Index; VAS, visual analog scale; DLQI, Dermatology Life Quality Index; IGA, Investigator Global Assessment; HS, hidradenitis suppurativa; HiSCR, Hidradenitis Suppurativa Clinical Response; QOL, quality of life; PGA, Physician Global Assessment; PG-7A, Physician Global 7-Point Assessment; POES, Physician Overall Erythema Severity; SASI, Sarcoidosis Activity and Severity Index. 
had prior treatment with conventional disease-modifying antirheumatic drugs or biologics, or both. PALACE 4 evaluated efficacy in treatment-naïve patients; standard dosing of apremilast was found to produce improvement in psoriatic arthritis in treatment-naïve and non-treatmentnaïve patients. ${ }^{4-6,22}$ In the 24 -week placebo-controlled phase of the PALACE 1 trial, the American College of Rheumatology (ACR) baseline composite measurement of $20 \%$ disease improvement, or ACR20, was achieved in $40 \%$ of patients randomized to the standard dosing regimen compared to $19 \%$ of patients receiving placebo, a statistically significant result $(P<.001) .{ }^{22}$

Evaluation of long-term study data is beyond the scope of this review, but those data suggest that disease outcomes continue to improve the longer therapy is utilized, with a greater percentage of patients achieving ACR20 as well as ACR50 (50\% improvement) and ACR70 (70\% improvement) responses. Indirect comparisons analyzing the cost and effectiveness for adalimumab, apremilast, and methotrexate in patients with psoriatic arthritis found that apremilast was less effective than adalimumab and as efficacious as methotrexate, though apremilast carries the highest price tag of these drugs. ${ }^{23}$

\section{Off-Label Uses}

Ease of oral administration and a favorable safety profile have prompted off-label study of apremilast in other inflammatory skin diseases, including atopic dermatitis, hidradenitis suppurativa, lichen planus, rosacea, alopecia areata, and cutaneous sarcoidosis. Publications with a minimum case series of 10 patients are included in the Table. ${ }^{24-32}$

\section{Use in the Military and Beyond}

Psoriasis and other inflammatory skin conditions are common in the military and can greatly hinder a service member's ability to perform their duties and remain ready to deploy. A history of psoriasis is disqualifying for military recruits, but early entry into service, misdiagnosis, and low or no burden of disease at time of entry into the service all contribute to a substantial population of active-duty service members who require treatment of psoriasis. ${ }^{33}$ Necessity dictates that treatment of this condition extend to theater operations; from 2008 to 2015, more than 3600 soldiers sought care for psoriasis while deployed to a combat theater. ${ }^{34}$

In some cases, poorly controlled inflammatory skin conditions lead to medical separation..$^{33}$ Although there are limited data on the use of apremilast in the military, its use during deployment for the treatment of psoriasis and psoriatic arthritis has been reported, with the great majority of service members retaining their deployable status even 1 year after the study period. ${ }^{35}$

The ideal medication for deployable military personnel should have low toxicity, simple storage, and minimal monitoring requirements, and it should not expose a service member to increased risk while in a combat theater. Worldwide deployability is a requirement for most military occupations. The risk for immunosuppression with targeted immune therapy must be fully weighed, as certain duty stations and deployments might increase the risk for exposure to Mycobacterium tuberculosis, endemic mycopathogens, hepatitis C virus, HIV, Leishmania, and Strongyloides. ${ }^{34}$

Furthermore, the tumor necrosis factor $\alpha$ inhibitors and IL-17 and IL-23 blockers used to treat psoriasis all require refrigeration; often, this requirement cannot be met in austere overseas settings. Additional requirements for laboratory monitoring, titration of medications, and frequent office visits might prohibit a service member from performing their duties, which, in turn, is detrimental to military readiness and the career of that service member.

Last, the Centers for Disease Control and Prevention recommend avoiding live virus vaccination while taking targeted immune therapy because of safety and effectiveness concerns during immunosuppression. ${ }^{36}$ This recommendation might disqualify military personnel from deployment to certain locations that require the protection that such vaccines afford. Therefore, apremilast is an ideal option for the military patient population, with many military-specific advantages.

Of course, the military is not the only population in whom ease of use and storage and simplified monitoring parameters are essential. Benefits of apremilast also may translate to patients who are placed in austere conditions or who participate in extended worldwide travel for work or leisure, such as government contractors who deploy in support of military operations, firefighters or national park employees who spend extended periods in resource-limited settings, and foreign-aid workers and diplomats who are engaged in frequent travel around the world. Furthermore, travel to certain regions might increase the risk for exposure to atypical pathogens as well as the desire for a therapeutic option that does not have potential to suppress the immune system. This subset of psoriasis patients might be better treated with novel agents such as apremilast than other drugs that would be the presumed standard of care in a domestic setting.

\section{Final Thoughts}

The benefits of apremilast translate to all patients in austere environments with limited resources and during times when immune function is of utmost concern. For military service members and many civilians in austere environments worldwide, apremilast could be considered a first-line systemic agent for psoriasis and psoriatic arthritis. In patients unable to use or tolerate other treatments, apremilast can be considered for off-label therapy (Table ${ }^{24-32}$ ). There are times when the approach to prescribing must look beyond primary efficacy, AE profile, and cost-to include occupation, environment, or duties - to select the optimal medication for a patient. 


\section{REFERENCES}

1. Hatemi G, Melikoglu M, Tunc R, et al. Apremilast for Behçet's syndrome-a phase 2, placebo-controlled study. $N$ Engl $\mathrm{J}$ Med. 2015;372:1510-1518. doi:10.1056/NEJMoa1408684

2. Papp K, Reich K, Leonardi CL, et al. Apremilast, an oral phosphodiesterase 4 (PDE4) inhibitor, in patients with moderate to severe plaque psoriasis: results of a phase III, randomized, controlled trial (Efficacy and Safety Trial Evaluating the Effects of Apremilast in Psoriasis [ESTEEM] 1). J Am Acad Dermatol. 2015;73:37-49. doi:10.1016/j. jaad.2015.03.049

3. Paul C, Cather J, Gooderham M, et al. Efficacy and safety of apremilast, an oral phosphodiesterase 4 inhibitor, in patients with moderate-tosevere plaque psoriasis over 52 weeks: a phase III, randomized controlled trial (ESTEEM 2). Br J Dermatol. 2015;173:1387-1399. doi:10.1111/ bjd.14164

4. Cutolo M, Myerson GE, Fleischmann RM, et al. A phase III, randomized, controlled trial of apremilast in patients with psoriatic arthritis: results of the PALACE 2 trial. J Rheumatol. 2016;43:1724-1734. doi:10.3899/jrheum.151376

5. Edwards CJ, Blanco FJ, Crowley J, et al. Apremilast, an oral phosphodiesterase 4 inhibitor, in patients with psoriatic arthritis and current skin involvement: a phase III, randomised, controlled trial (PALACE 3). Ann Rheum Dis. 2016;75:1065-1073. doi:10.1136/annrheumdis-2015-207963

6. Wells AF, Edwards CJ, Kivitz AJ, et al. Apremilast monotherapy in DMARD-naive psoriatic arthritis patients: results of the randomized, placebo-controlled PALACE 4 trial. Rheumatology (Oxford) 2018;57:1253-1263. doi:10.1093/rheumatology/key032

7. Niaki OZ, Anadkat MJ, Chen ST, et al. Navigating immunosuppression in a pandemic: a guide for the dermatologist from the COVID Task Force of the Medical Dermatology Society and Society of Dermatology Hospitalists. J Am Acad Dermatol. 2020;83:1150-1159. doi:10.1016/j. jaad.2020.06.051

8. Paller AS, Hong Y, Becker EM, et al. Pharmacokinetics and safety of apremilast in pediatric patients with moderate to severe plaque psoriasis: results from a phase 2 open-label study. J Am Acad Dermatol. 2020;82:389-397. doi:10.1016/j.jaad.2019.08.019

9. Rademaker M, Agnew K, Andrews M, et al. Psoriasis in those planning a family, pregnant or breast-feeding. The Australasian Psoriasis Collaboration. Australas J Dermatol. 2018;59:86-100. doi:10.1111/ajd.12641

10. Otezla. Prescribing information. Amgen Inc; June 2020. Accessed March 13, 2021. www.pi.amgen.com/ /media/amgen/repositorysites/ pi-amgen-com/otezla/otezla_pi_english.ashx

11. Otezla. Product monograph. Amgen Canada Inc; Revised August 2020. Accessed March 13, 2021. www.amgen.ca/products/ /media/ FB841218E06B4508B0E7213BC578E641.ashx

12. Augustin M, Kleyn CE, Conrad C, et al. Characteristics and outcomes of patients treated with apremilast in the real world: Results from the APPRECIATE study. J Eur Acad Dermatol Venereol. 2020;35:123-134. doi:10.1111/jdv.16431

13. Papadavid E, Rompoti N, Theodoropoulos K, et al. Real-world data on the efficacy and safety of apremilast in patients with moderateto-severe plaque psoriasis. J Eur Acad Dermatol Venereol. 2018;32:11731179. doi:10.1111/jdv.14832

14. Wong TH, Sinclair S, Smith B, et al. Real-world, single-centre experience of apremilast for the treatment of moderate to severe psoriasis. Clin Exp Dermatol. 2017;42:675-676. doi:10.1111/ced.13150

15. Saurat, J-H, Stingl G, Dubertret L, et al; CHAMPION Study Investigators. Efficacy and safety results from the randomized controlled comparative study of adalimumab vs. methotrexate vs. placebo in patients with psoriasis (CHAMPION). Br J Dermatol. 2008;158:558566. doi:10.1111/j.1365-2133.2007.08315.x

16. Kimball AB, Papp KA, Wasfi Y, et al; PHOENIX 1 Investigators. Longterm efficacy of ustekinumab in patients with moderate-to-severe psoriasis treated for up to 5 years in the PHOENIX 1 study. J Eur Acad Dermatol Venereol. 2013;27:1535-1545. doi:10.1111/jdv.12046

17. Langley, RG, Elewski BE, Lebwohl M, et al; ERASURE Study Group; FIXTURE Study Group. Secukinumab in plaque psoriasis-results of two phase 3 trials. N Engl J Med. 2014;371:326-338. doi:10.1056/NEJMoa1314258
18. Lebwohl M, Strober B, Menter A, et al. Phase 3 studies comparing brodalumab with ustekinumab in psoriasis. NEnglJMed. 2015;373:13181328. doi:10.1056/NEJMoa1503824

19. Papp KA, Leonaridi CL, Blauvelt A, et al. Ixekizumab treatment for psoriasis: integrated efficacy analysis of three double-blinded, controlled studies (UNCOVER-1, UNCOVER-2, UNCOVER-3). Br J Dermatol. 2018;178:674-681. doi:10.1111/bjd.16050

20. Kromer C, Celis D, Sonntag D, et al. Biologicals and small molecules in psoriasis: a systematic review of economic evaluations. PloS One. 2018;13:e0189765. doi:10.1371/journal.pone.0189765

21. Armstrong AW, Betts KA, Sundaram M, et al. Comparative efficacy and incremental cost per responder of methotrexate versus apremilast for methotrexate-naïve patients with psoriasis. J Am Acad Dermatol. 2016;75:740-746. doi:10.1016/j.jaad.2016.05.040

22. Kavanaugh A, Mease PJ, Gomez-Reino JJ, et al. Treatment of psoriatic arthritis in a phase 3 randomised, placebo-controlled trial with apremilast, an oral phosphodiesterase 4 inhibitor. Ann Rheum Dis. 2014;73:1020-1026. doi:10.1136/annrheumdis-2013-205056

23. Betts KA, Griffith J, Friedman A, et al. An indirect comparison and cost per responder analysis of adalimumab, methotrexate and apremilast in the treatment of methotrexate-naive patients with psoriatic arthritis. Curr Med Res Opin. 2016;32:721-729. doi:10.1185/03007995.2016.1140026

24. Simpson EL, Imafuku S, Poulin Y, et al. A phase 2 randomized trial of apremilast in patients with atopic dermatitis. J Invest Dermatol. 2019;139:1063-1072. doi:10.1016/j.jid.2018.10.043

25. Samrao A, Berry TM, Goreshi R, et al. A pilot study of an oral phosphodiesterase inhibitor (apremilast) for atopic dermatitis in adults. Arch Dermatol. 2012;148:890-897. doi:10.1001/archdermatol.2012.812

26. Volf EM, Au S-C, Dumont N, et al. A phase 2, open-label, investigatorinitiated study to evaluate the safety and efficacy of apremilast in subjects with recalcitrant allergic contact or atopic dermatitis. J Drugs Dermatol. 2012;11:341-346.

27. Vossen ARJV, van Doorn MBA, van der Zee HH, et al. Apremilast for moderate hidradenitis suppurativa: results of a randomized controlled trial. J Am Acad Dermatol. 2019;80:80-88. doi:10.1016/j.jaad.2018.06.046

28. Kerdel FR, Azevedo FA, Don CK, et al. Apremilast for the treatment of mild-to-moderate hidradenitis suppurativa in a prospective, openlabel, phase 2 study. J Drugs Dermatol. 2019;18:170-176.

29. Paul J, Foss CE, Hirano SA, et al. An open-label pilot study of apremilast for the treatment of moderate to severe lichen planus: a case series. J Am Acad Dermatol. 2013;68:255-261. doi:10.1016/j.jaad.2012.07.014

30. Thompson BJ, Furniss M, Zhao W, et al. An oral phosphodiesterase inhibitor (apremilast) for inflammatory rosacea in adults: a pilot study. JAMA Dermatol. 2014;150:1013-1014. doi:10.1001/jamadermatol.2013.10526

31. Mikhaylov D, Pavel A, Yao C, et al. A randomized placebo-controlled single-center pilot study of the safety and efficacy of apremilast in subjects with moderate-to-severe alopecia areata. Arch Dermatol Res. 2019;311(1):29-36. doi:10.1007/s00403-018-1876-y

32. Baughman RP, Judson MA, Ingledue R, et al. Efficacy and safety of apremilast in chronic cutaneous sarcoidosis. Arch Dermatol. 2012;148:262264. doi:10.1001/archdermatol.2011.301

33. Navy Medicine, US Navy. Manual of the Medical Department (MANMED), NAVMED P-117. Chapter 15. Updated October 20, 2020. Accessed March 13, 2021. https://www.med.navy.mil/directives/Pages /NAVMEDP-MANMED.aspx

34. Rosenberg A, Meyerle J. The use of apremilast to treat psoriasis during deployment. Mil Med. 2017;182:1628-1631. doi:10.7205/MILMEDD-17-00047

35. Price AD, Wagler VD, Donaldson C, et al. The effects of apremilast therapy on deployability in active duty US Army soldiers with plaque psoriasis and psoriatic arthritis [published online October 30, 2020]. J Clin Rheumatol. doi:10.1097/RHU.0000000000001601

36. Centers for Disease Control and Prevention. Epidemiology and Prevention of Vaccine-Preventable Diseases. Hamborsky J, Kroger A, Wolfe S, eds. 13th ed. Washington D.C. Public Health Foundation, 2015. Accessed March 25, 2021; https://www.cdc.gov/vaccines/pubs /pinkbook/downloads/table-of-contents.pdf 